\title{
Desain LKS Berbasis Karakter Komunikasi Matematis dan Kemandirian dengan Pendekatan PMR
}

\author{
Nurhadijah $^{1) *}$, Sulis Janu Hartati ${ }^{2)}$, Lusiana Prastiwi ${ }^{3)}$ \\ ${ }^{1}$ Pendidikan Matematika, Universitas Dr. Soetomo, Surabaya, Indonesia; \\ *nurhadijah958@gmail.com \\ ${ }^{2}$ Pendidikan Matematika, Universitas Dr. Soetomo, Surabaya, Indonesia; \\ sulis.janu@unitomo.ac.id \\ ${ }^{3}$ Pendidikan Matematika, Universitas Dr. Soetomo, Surabaya, Indonesia; \\ lusiana.prastiwi@unitomo.ac.id
}

\begin{abstract}
Abstrak. Penelitian ini didasarkan pada pembelajaran matematika yang umumnya berpusat pada guru, yang dianggap mampu membuat siswa dapat memahami materi yang diberikan. Sedangkan, dalam implementasi kurikulum 2013 siswa harus berperan aktif dalam pembelajaran. Teknik yang digunakan penelitian ini adalah observasi, wawancara, angket, tes dan dokumentasi. Model pembelajaran dalam penelitian ini menggunakan pendekatan pembelajaran matematika realistik. Tujuan dari penelitian ini untuk mendesain LKS dengan pendekatan matematika realistik yang mampu mengembangkan karakter komunikasi matematis dan kemandirian pada siswa. Instrumen penelitian yang digunakan adalah pedoman wawancara, pedoman observasi, LKS, lembar penilaian ahli, angket respon guru dan siswa. Hasil penelitian menunjukkan bahwa LKS yang dikembangkan dikatakan layak digunakan berdasarkan skor 4.2 dan 3.75 dari ahli materi dan ahli media. Serta skor 26.3 dan 75.97 dari siswa dan guru yang menunjukkan LKS menarik. Jadi disimpulkan bahwa LKS layak digunakan serta menarik perhatian guru dan siswa.

Kata Kunci: LKS, komunikasi matematis, kemandirian, ADDIE, pembelajaran matematika realistik
\end{abstract}

\begin{abstract}
This research is based on learning mathematics which is generally centered on teachers, who are considered able to make students understand the material provided. Whereas, in the implementation of curriculum 2013 students should play an active role in learning. The techniques used in this research are observations, interviews, polls, tests and documentation. The learning Model in this study uses a realistic mathematical learning approach. The purpose of this research is to design the LKS with a realistic mathematical approach that is capable of developing mathematical and self-reliance communication characters in students. The research instruments used are interview guidelines, observation guidelines, LKS, expert assessment sheets, teacher and student response polls. The results showed that the LKS developed were said to be worthy of use based on the 4.2 and 3.75 scores of material experts and media experts. As well as scores 26.3 and 75.97 of students and teachers who show interesting LKS. So it concludes that the LKS are worth using and attracting teachers and students ' attention.
\end{abstract}


Keywords: LKS, mathematical communication, self-reliance, ADDIE, realistic mathematics learning

\section{Pendahuluan}

Berbagai macam strategi dan kurikulum telah dikembangkan dalam dunia pendidikan Indonesia oleh pemerintah, dengan kurikulum yang baik diharapkan dapat menjadikan Indonesia sebagai bangsa yang bermartabat dan memiliki masyarakat dengan nilai jual yang tinggi dalam bidang pendidikan sehingga dapat bersaing dengan bangsa - bangsa lain dalam taraf internasional. Hal ini dapat terwujud jika penerapan kurikulum benar - benar dapat menghasilkan masyarakat yang kreatif, inovatif, produktif, dan berkarakter. Pernyataan dan harapan tersebut tentu sangat besar hubungannya dengan kurikulum yang dianut oleh dunia pendidikan Indonesia pada sekarang ini yaitu Kurikulum 2013.

Kusnadi mengemukakan bahwa kurikulum 2013 ialah kurikulum yang menitikberatkan pada pendidikan karakter, terutama tahap awal yang merupakan fondasi atau dasar pada tahap berikut (Kusnadi et al., 2014). Kurikulum 2013 adalah jenis kurikulum yang mengutamakan pendidikan karakter, kepahaman, dan skill siswa. Dua dari banyaknya karakter yang sangat penting dikembangkan adalah karakter komunikasi matematis dan kemandirian siswa. Menurut (Nofrianto et al., 2017) komunikasi matematis dapat diartikan sebagai kemampuan siswa dalam mengekspresikan sesuatu yang ia ketahui melalui percakapan dialog atau saling berhubungan yang mungkin terjadi dilingkungan kelas, dimana terjadi penyaluran pesan. Pesan yang disalurkan berupa materi matematika yang dipelajari siswa, misalnya menentuan konsep, strategi penyelesaian masalah ataupun rumus. Sedangkan kemandirian adalah proses yang membantu siswa dalam mengatur pikiran, tingkah laku, dan perasaan mereka agar membuat mereka berhasil dalam menjalani pengalaman belajar mereka. (Istianah, 2013)

Hasil observasi awal yang dilaksanakan di SMA Islam Parlaungan pada tanggal 12 Maret 2020, ditemukan permasalahan dalam komunikasi matematis dan kemandirian siswa. Ini terlihat dari dalam menyelesaikan tugas-tugas siswa terbiasa menyontek pekerjaan teman serta tidak dapat menyalurkan ide-ide dalam bentuk tertulis maupun lisan. Selain itu, bahan ajar tambahan berupa LKS kurang mengarahkan siswa untuk mengembangkan karakter komunikasi matematis dan kemandirian siswa. Pembelajaran cenderung berpusat pada guru. Padahal dalam kurikulum 2013 
guru dituntut untuk membuat pembelajaran yang menarik dan memotivasi agar mampu mengembangkan karakter siswa.

Dalam desain LKS perlu diterapkan suatu pendekatan, salah satunya adalah pendekatan pembelajaran matematika realistik. Menurut (Rismaratri \& Nuryadi, 2018) menyatakan pembelajaran matematika realistik (PMR) merupakan pendekatan pengajaran yang berhubungan dengan sesuatu yang nyata bagi peserta didik yang lebih menekankan pada keterampilan dalam proses matematika, diskusi dan kolaborasi antar siswa, adanya interaksi sesama teman sekelas yang mengakibatkan peserta didik mampu menentukan sendiri strategi dalam menyelesaikan suatu permasalahan matematika, baik secara individu ataupun kelompok.

Berdasarkan hasil penelitian yang dilakukan oleh Darmawati, Edi Tandililing, Agung Hartoyo pada tahun 2016 mengenai pengembangan perangkat pembelajaran matematika berbasis pembelajaran matematika realistik untuk meningkatkan kemampuan komunikasi matematis siswa SMP dideskripsikan bahwa kemampuan komunikasi matematis siwa SMP mengalami peningkatan setelah digunakan metode pendekatan pembelajaran matematika realistik. Selain itu, Pada tahun 2014 Listiyana Dewi melakukan penelitian mengenai peningkatan kemandirian dan hasil belajar siswa kelas VIII melalui pendekatan PMR, hasil penelitian menunjukkan adanya peningkatan kemandirian dan hasil belajar dengan menggunakan pendekatan PMR.

Dari pemaparan diatas dapat disimpulkan bahwa LKS dengan pendekatan pembelajaran matematika realistik dapat membantu mengembangkan karakter komunikasi matematis dan kemandirian siswa. Sehingga dalam penelitian ini dikaji tentang "Desain LKS Berbasis Karakter Komunikasi Matematis dan Kemandirian Siswa dengan Pendekatan Pembelajaran Matematika Realistik". Rumusan masalah dalam penelitian ini adalah bagaimana LKS berbasis karakter komunikasi matematis dan kemandirian siswa dengan pendekatan pembelajaran matematika realistik yang dikembangkan memenuhi kriteria valid dan menarik. Tujuan penelitian adalah untuk megetahui pengembangan LKS berbasis karakter komunikasi matematis dan kemandirian siswa dengan pendekatan pembelajaran matematika realistik pada pembelajaran matematika yang valid dan menarik. 


\section{Metode}

Jenis penelitian yang digunakan adalah penelitian pengembangan atau Research and Development (RED) dengan model ADDIE (analysis, design, development, implementation, dan evaluation). Namun, dalam penelitian ini hanya 2 tahap yakni: analysis dan design. Tahap-tahap penelitian pengembangan LKS yang dilakukan sebagai berikut.

a. Analysis

1) Analisis kebutuhan

Pada tahap ini dilakukan pengumpulan informasi mengenai perangkat pembelajaran yang perlu dikembangkan. Pengumpulan informasi dilakukan dengan wawancara terhadap guru matematika.

2) Analisis kurikulum

Analisis kurikulum dilakukan dengan mengkaji kurikulum yang digunakan, yaitu kurikulum 2013. Hal-hal yang dianalisis adalah kompetensi dasar, kompetensi inti, metode, bahan ajar, dan strategi pembelajaran yang digunakan serta standar proses yang sesuai dengan kurikulum 2013.

3) Analisis Karakteristik Siswa

Analisis ini dilakukan dengan melihat catatan siswa, kajian teori, dan pengamatan saat pembelajaran.

b. Design

Penyusunan desain adalah sebagai berikut:

1) Penyusunan Desain LKS

Rancangan penelitian pengembangan LKS matematika berbasis pendekatan matematika realistik untuk meningkatkan kemampuan komunikasi matematis dan kemandirian siswa dilakukan dengan langkahlangkah sebagai berikut:

a) Menentukan Judul LKS

Judul LKS ditentukan berdasarkan kompetensi dasar (KD), indikatorindikator, dan materi yang tercantum dalam kurikulum.

b) Menentukan Desain LKS

Langkah-langkah yang akan dilakukan dalam penulisan LKS sebagai berikut:

a) Perumusan kompetensi dasar

b) Perancangan dari sisi media

c) Penyusunan topik materi

d) Menentukan bentuk evaluasi

Copyright (c) 2020

Buana Matematika :

Jurnal Ilmiah Matematika dan Pendidikan Matematika 
2) Penyusunan Desain Instrumen

Hal ini bertujuan agar alat untuk menilai LKS yang dikembangkan bisa benar-benar valid. Sebelum digunakan dalam penilaian LKS, instrumen penilaian yang dikembangkan akan divalidasi terlebih dahulu.

Teknik pengumpulan data pada desain LKS berbasis karakter komunikasi matematis dan kemandirian siswa dengan pendekatan pembelajaran matematika realistik berupa metode observasi, angket, wawancara, tes dan dokumentasi. Instrumen penelitian berupa pedoman wawancara, pedoman observasi, LKS, angket validasi, angket respon dan tes.

Hasil lembar validasi dari validator terhadap aspek yang disajikan pada tabel 1 berikut sebagai berikut.

Tabel 1. Kriteria Penilaian Kualitas

\begin{tabular}{cc}
\hline Rentang Skor & Kriteria \\
\hline $\bar{X}>X_{i}+1,8 S b i$ & Sangat baik \\
$X i+0,6 S b i<\bar{X} \leq X i+1,8 S b i$ & Baik \\
$X i-0,6 S b i<\bar{X} \leq X i+0,6 S b i$ & Cukup \\
$X i-1,8 S b i<\bar{X} \leq X i-0,6 S b i$ & Kurang baik \\
$\bar{X} \leq X_{i}-1,8 S b i$ & Sangat Kurang Baik \\
\hline
\end{tabular}

Keterangan:

$\bar{X}=$ Skor empiris yang diperoleh

$\mathrm{X} \mathrm{i}=$ rerata ideal $=1 / 2(\max -\min )$

Sbi $=$ simpangan baku $=1 / 6(\max -\min )$

Dengan pedoman kriteria pengkategori validitas LKS, dapat dilihat pada tabel 2.

Tabel 2. Kriteria Skor Penilaian Kualitas

\begin{tabular}{cc}
\hline Rentang Skor & Kriteria \\
\hline $\bar{X}>4,2$ & Sangat Layak \\
$3,4<\bar{X} \leq 4,2$ & Layak \\
$2,6<\bar{X} \leq 3,4$ & Cukup Layak \\
$1,8<\bar{X} \leq 2,6$ & Kurang Layak \\
$\bar{X} \leq 1,8$ & Sangat Kurang Layak \\
\hline
\end{tabular}

Hasil lembar angket respon guru dapat menggunakan rumus;

Skor total pertanyaan $=($ Jumlah guru yang menjawab SB $\times 5)+($ Jumlah guru yang menjawab $\mathrm{B} \times 4)+($ Jumlah guru yang menjawab $\mathrm{C} \times 3)+($ Jumlah guru yang menjawab $\mathrm{K} \times 2$ ) + (Jumlah guru yang menjawab SK $\times 1$ ).

\section{Buana Matematika :}

Jurnal Ilmiah Matematika dan Pendidikan Matematika 
Dengan pedoman kriteria pengkategori validitas LKS, dapat dilihat pada tabel 3.

Tabel 3. Skor Hasil Angket Guru

\begin{tabular}{cc}
\hline Skor & Kriteria \\
\hline $75.7-90$ & Sangat Baik \\
$61.3-75.6$ & Baik \\
$46.5-61.2$ & Cukup \\
$32.5-46.4$ & Kurang Baik \\
$18-32.4$ & Sangat Kurang Baik \\
\hline
\end{tabular}

Hasil lembar angket respon guru dapat menggunakan rumus;

Skor total pertanyaan $=($ Jumlah guru yang menjawab SB $\times 5)+($ Jumlah guru yang menjawab $\mathrm{B} \times 4)+($ Jumlah guru yang menjawab $\mathrm{C} \times 3)+($ Jumlah guru yang menjawab $\mathrm{K} \times 2)+($ Jumlah guru yang menjawab $\mathrm{SK} \times 1$ ).

Dengan pedoman kriteria pengkategori validitas LKS, dapat dilihat pada tabel 4.

Tabel 4. Skor Hasil Angket Siswa

\begin{tabular}{cc}
\hline Skor & Kriteria \\
\hline $29.5-35$ & Sangat Menarik \\
$23.9-29.4$ & Menarik \\
$18.3-23.8$ & Cukup \\
$12.7-18.2$ & Kurang Baik \\
$7-12.6$ & Sangat Kurang Baik \\
\hline
\end{tabular}

\section{Hasil dan Pembahasan}

Langkah - langkah yang dilakukan pada penelitian ini yakni;

1) tahap analysis (analisis) meliputi analisis kenutuhan, analisis kurikulum, dan analisis karakteristik siswa. Dari hasil analisis kebutuhan, diperoleh bahwa pembelajaran masih berpusat pada guru sehingga siswa tidak dapat mengembangkan karakter komunikasi matematis dan kemandirian. Berdasarkan hasil analisis kurikulum, diperoleh bahwa siswa SMA sudah menggunakan kurikulum 2013 namun dalam implemantasinya masih menggunakan metode pembelajaran konvensional. Selain itu hasil analisis karakteristik siswa menunjukkan bahwa siswa cenderung tidak memiliki rasa percaya diri baik dalam menyampaikan pendapat saat diskusi maupun dalam mengerjakan latihan.

2) tahap design (perencanaan). Kegiatan pada tahap ini adalah mendesain LKS, rancangan awal, validasi produk.

a) Hasil dari mendesain LKS dapat dilihat pada gambar dibawah ini.

Copyright $@ 2020$

\section{Buana Matematika :}

Jurnal Ilmiah Matematika dan Pendidikan Matematika 


\section{LEMBAR KERJA SISWA \\ Bertasts pembefataran Malemalik nealistik tpman}

TRIGONOMETRI

Nama

No Absen

Alamat

Gambar 1. Cover LKS berisi Identitas Siswa

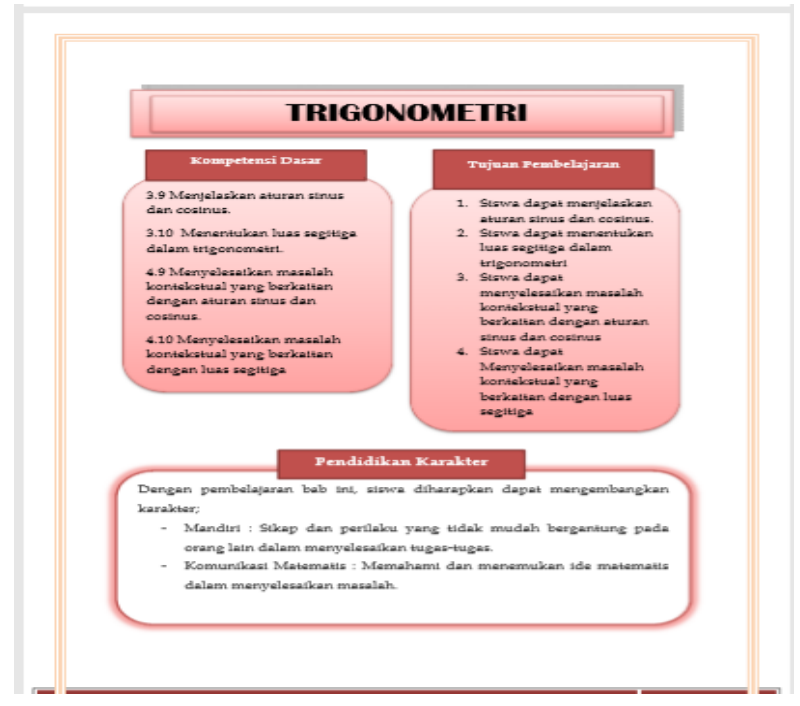

Gambar 2. Kompetensi Dasar dan Tujuan Pembelajaran

b) Validasi produk

1) Hasil Validasi ahli

Tabel 5. Hasil Validasi Ahli

\begin{tabular}{cccc}
\hline No. & Instrumen & Rata-rata & Kriteria \\
\hline 1 & Lembar Ahli Materi & 4.2 & Layak \\
2 & Lembar Ahli Media & 3.75 & Layak \\
\hline
\end{tabular}

Berdasarkan hasil validasi ahli pada tabel menggambarkan rata-rata uji validitas LKS termasuk kategori layak.

Copyright $@ 2020$

Buana Matematika :

Jurnal Ilmiah Matematika dan Pendidikan Matematika 
2) Hasil respon guru

Berdasarkan hasil angket terkait respon guru terhadap LKS berbasis karakter komunikasi matematis dan kemandirian dengan pendekatan pembelajaran matematika realistik yang telah diberikan melalui google form memperoleh rata-rata skor 75.95. Dalam tabel kriteria menurut Widoyoko, LKS berbasis karakter komunikasi matematis dan kemandirian dengan pendekatan pembelajaran matematika realistik termasuk dalam kriteria "Sangat Baik"

3) Hasil respon Siswa

Berdasarkan hasil angket terkait respon siswa terhadap LKS berbasis karakter komunikasi matematis dan kemandirian dengan pendekatan pembelajaran matematika realistik yang telah diberikan melalui google form memperoleh rata-rata skor 26.3. Dalam tabel kriteria menurut Widoyoko, LKS berbasis karakter komunikasi matematis dan kemandirian dengan pendekatan pembelajaran matematika realistik termasuk dalam kriteria "Menarik"

\section{Simpulan}

Berdasarkan pada kajian pustaka yang didukung hasil analisis data dan pengujian hipotesis yang telah diuraikan pada BAB IV serta mengacu pada rumusan masalah maka dapat ditarik kesimpulan sebagai berikut :

1. Desain pengembangan LKS berbasis karakter komunikasi matematis dan kemandirian dengan pendekatan pembelajaran matematika realistik dikembangkan dengan model ADDIE sampai pada tahapan design dikarenakan kondisi dan situasi.

2. Desain pengembangan LKS berbasis karakter komunikasi matematis dan kemandirian dengan pendekatan pembelajaran matematika realistik dapat dikatakan layak digunakan. Hal ini berdasarkan hasil validasi dari ahli materi dan ahli media. Hasil validasi tersebut memperoleh rata-rata skor 4.2 dari ahli materi dan rata-rata skor 3.75 dari ahli media yang termasuk dalam kategori "Layak"

3. Desain LKS berbasis karakter komunikasi matematis dan kemandirian dengan pendekatan pembelajaran matematika realistik dapat dikatakan menarik. Hal ini berdasarkan hasil angket respon guru dan respon siswa. Hasil angket respon guru menunjukkan skor rata-rata 75.95 dan termasuk dalam kategori "sangat baik". Selain itu, hasil angket respon siswa mendapatkan skor 26.3 dan termasuk dalam kategori "menarik".

Copyright $@ 2020$

Buana Matematika :

Jurnal Ilmiah Matematika dan Pendidikan Matematika 


\section{Daftar Pustaka}

Endang, Mulyatiningsih. (2013). Metode Penelitian Terapan Bidang Pendidikan. Bandung:ALFABETA

Widoyoko, E. P. (2009). Evaluasi program pembelajaran (Vol. 91). Yogyakarta: Pustaka Pelajar.

Istianah, E. (2013). Meningkatkan Kemampuan Berpikir Kritis Dan Kreatif Matematik Dengan Pendekatan Model Eliciting Activities (Meas) Pada Siswa Sma. Infinity Journal, 2(1), 43. https://doi.org/10.22460/infinity.v2i1.23

Kusnadi, D., Tahmir, S., \& Minggi, I. (2014). Implementasi Kurikulum 2013 dalam Pembelajaran Matematika di SMA Negeri 1 Makassar. MaPan: Jurnal Matematika Dan Pembelajaran, 2(1), 123-135. https://doi.org/10.24252/mapan.2014v2n1a9

Nofrianto, A., Maryuni, N., \& Amri, M. A. (2017). Komunikasi Matematis Siswa: Pengaruh Pendekatan Matematika Realistik. Jurnal Gantang, 2(2), 113-121. https://doi.org/10.31629/jg.v2i2.199

Nurhalim, M. (1970). Optimalisasi Kurikulum Aktual Dan Kurikulum Tersembunyi Dalam Kurikulum 2013. INSANIA: Jurnal Pemikiran Alternatif Kependidikan, 19(1), 115-132. https://doi.org/10.24090/insania.v19i1.466

Rismaratri, D., \& Nuryadi, N. (2018). Pengaruh Model Pembelajaran Quantum Dengan Pendekatan Realistic Mathematic Education (RME) Terhadap Kemampuan Berfikir Kreatif Dan Motivasi Belajar Matematika. Jurnal $\begin{array}{llll}\text { Edukasi Matematika Dan } & \end{array}$ https://doi.org/10.25273/jems.v5i2.2012

\section{Riwayat Hidup Penulis}

\section{Nurhadijah}

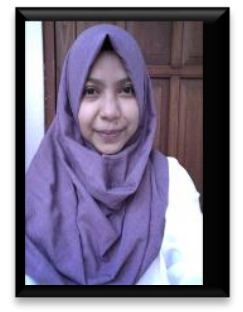

Lahir di Bangka, 08 Januari 1998. Mahasiswa di Universitas Dr. Soetomo. Studi S1 Pendidikan Matematika Universitas Dr Soetomo, Surabaya, lulus tahun 2020. 


\section{Sulis Janu Hartati}

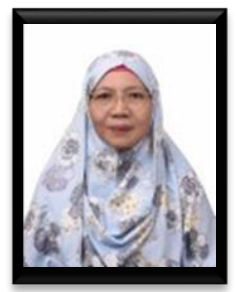

Lahir di Kediri, 22 Januari 1964. Dosen matematika di Universitas Dr Soetomo Surabaya. Studi S1 Matematika Universitas Airlangga, Surabaya, lulus tahun 1987. Studi S2 Teknik Elektro-Informatika Institut Teknologi Sepuluh Nopember, Surabaya, lulus tahun 1998. Studi S3 Pendidikan Matematika Universitas Negeri Surabaya, lulus tahun 2012

\section{Lusiana Prastiwi}

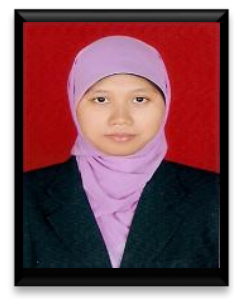

Lahir di Surabaya, 19 Februari 1987. Dosen matematika di Universitas Dr Soetomo Surabaya. Studi S1 Matematika Institut Teknologi Sepuluh Nopember, Surabaya, lulus tahun 2009. Studi S2 Matematika Institut Teknologi Sepuluh Nopember, Surabaya, lulus tahun 2013. 